OPEN ACCESS

Edited by:

Viviana Noemí Lemos,

Consejo Nacional de Investigaciones

Científicas y Técnicas (CONICET),

Argentina

Reviewed by:

Carbonero Martín Miguel Angel,

University of Valladolid, Spain

Justine Megan Gatt,

Neuroscience Research Australia,

Australia

*Correspondence:

Tania Vieites

t.vieites@udc.es

Specialty section:

This article was submitted to

Health Psychology,

a section of the journa

Frontiers in Psychology

Received: 11 February 2021

Accepted: 17 May 2021

Published: 08 June 2021

Citation:

Rodríguez S, Valle A, Piñeiro I, González-Suárez R, Díaz FM and

Vieites T (2021) COVID-19

Lockdown: Key Factors in Citizens'

Stress.

Front. Psychol. 12:666891. doi: 10.3389/fpsyg.2021.666891

\section{COVID-19 Lockdown: Key Factors in Citizens' Stress}

\author{
Susana Rodríguez, Antonio Valle, Isabel Piñeiro, Rocío González-Suárez, \\ Fátima M. Díaz and Tania Vieites*
}

Departamento de Psicología, Grupo de Investigación en Psicología Educativa (GIPED), University of A Coruña, A Coruña, Spain

Background: Confinement due to COVID-19 can have a short- and long-term impact on mental health (increased levels of stress and anxiety and emotional upheaval) and on people's quality of life. Knowing what factors are behind the stress can benefit the development of strategies and resources for future situations of a similar nature. The purpose of this study is to examine the incidence of a series of sociodemographic factors, confinement conditions, and work situation on the stress reported by confined citizens.

Method: The sample is made up of 2008 citizens (19.9\% men), the Perceived Stress Scale of 14 items (PSS-14) was used to assess the stress level of the population, as well as a sociodemographic questionnaire and different questions aimed at obtain information about the characteristics of the confinement and the employment situation. Data were collected using exponential snowball-type non-probability sampling.

Results: The results suggest that sociodemographic factors such as age, gender, and income level could be good predictors of confinement stress. Post-confinement work expectancy along with pre-confinement working conditions can be key to protecting the well-being of confined populations.

Limitations: This is a transversal study that forces us to be cautious with causal interpretations. The questionnaire was administered online, which means it excluded a good proportion of the population.

Conclusion: The perception of stress being higher in women than men, with the lowest stress in older people and those with higher reported incomes. Stress levels increase as populations spend more weeks in confinement and the pre-confinement work situation seems key to protecting the well-being of the population. A lower stress is observed among stable couples without children confined in residential or suburban areas. Low income or economic instability is associated with a higher rate of stress and anxiety. The results can contribute to prioritizing actions and aid by contributing to the formation of teams and the design of tools for work in the current pandemic situation.

Keywords: health and well-being, stress, COVID-19, context effects, survey research

\section{INTRODUCTION}

In order to tackle the COVID-19 pandemic, the greatest social-healthcare challenge at the moment, unprecedented restrictions on daily life have been placed on citizens all over the world. Confinement to the home, which is what most governments chose, may have short- and long-term impacts 
on people's mental health and quality of life. In this novel context, we look at a series of factors that may explain people's stress response during their confinement due to COVID-19. The importance of this study lies in the opportunity to understand the factors behind confinement stress, facilitating the development and resources to deal with similar situations in the future.

\section{Stress and Well-Being}

MERS-Cov in Korea in 2013, Serious Acute Respiratory Syndrome (SARS), and Ebola are three examples of relatively recent serious health emergencies, which had different effects on the psychological and physical health of healthcare workers and the general population. Increased stress, anxiety, emotional unrest, worry, and depressive symptoms are the most commonly reported effects in populations that have suffered confinement or a large-scale health emergency of this type (Mohammed et al., 2015; Jalloh et al., 2018; Min et al., 2018; Brooks et al., 2020; Molero et al., 2020).

Stress is conceptualized as a person's response process when they perceive a situation or event as threatening or overwhelming due to them not having sufficient resources to deal with it (Meléndez et al., 2018). In the current situation of confinement, because of COVID-19, the perception of not controlling the environment and the sensation of being overwhelmed by events may trigger the stress process in a population (Meléndez et al., 2018). This situation demands individuals to make increased efforts and potentially compromises their health (Quick et al., 1987; Greenberg et al., 2002; Durán, 2010; Sánchez, 2013) along with the various dimensions of their well-being (Cohen and Wills, 1985; Cohen and Williamson, 1991; Cohen and Herbert, 1996; McEwen, 1998; Trujillo and González-Cabrera, 2007).

\section{Stress and Sociodemographic Factors}

In a recent systematic review, Brooks et al. (2020) stated that sociodemographic factors may be the predictors with the greatest psychological impact on the stress of confinement. Being female has been associated with more depressive symptoms, with more anxiety, and more reported stress during the periods of confinement (Taylor et al., 2008; González-Sanguino et al., 2020; Kang et al., 2020; Pappa et al., 2020; Qiu et al., 2020; Wang et al., 2020a,b). In addition, although we have studies that finding no significant relationship between age and stress (Wang et al., 2020a), most authors suggest that people at younger (non-infant) ages would demonstrate higher rates of stress during confinement. Although those studies refer to people aged between 18 and 25 or 21-38 years old (Taylor et al., 2008; Kang et al., 2020; Ozamiz-Etxebarria et al., 2020; Qiu et al., 2020; Shanahan et al., 2020; Wang et al., 2020b), one might expect, as noted by González-Sanguino et al. (2020), age be a protective factor against the psychological impact of stress.

During a pandemic, one of the measures that governments usually employ is the cancellation of a large part of productive activity to safeguard workers and reduce transmission. This cancellation of work means workers interrupting their professional activity, often accompanied by a suspension or reduction of income. This economic instability may explain not only distress during the confinement, but also anger and anxiety once the lockdown has been lifted (Brooks et al., 2020; Lozano-Vargas, 2020; Shanahan et al., 2020; Wang et al., 2020a).
Although there are studies suggesting that educational levels do not have significant associations with indices of population stress (Hawryluck et al., 2004; Brooks et al., 2020), we have included this sociodemographic parameter in order to contribute to clarifying contradictions. Lozano-Vargas (2020) and Qiu et al. (2020) noted greater stress in individuals with higher educational qualifications (university level) based on greater awareness and understanding of the risks of the illness. However, studies, such as Wang et al. (2020a), reported that it was precisely those with the least educational qualifications who reported higher stress owing to the perception of vulnerability, lack of knowledge, and their difficulty in understanding the situation. We have also included civil or marital status as a sociodemographic variable, despite having some evidence that it cannot be significantly associated with perceived stress during the periods of confinement (Brooks et al., 2020; Lozano-Vargas, 2020; Wang et al., 2020a), as one might expect people in stable partnerships to feel more able to call on their support network of friends and family than single people, for example (Ma et al., 2020).

\section{Stress and Conditions of Confinement}

In addition to sociodemographic characteristics, the condition in which one is confined in the home, such as whether it is with children or not, the place itself, and the length of time, may affect people's levels of stress. Thus, apart from the stress classically associated with playing the parent-child role (Abidin, 1997; Raphael et al., 2010), one might expect that being in lockdown with children may be an additional challenge to parents who are obliged to balance full-time childcare with their own working responsibilities (Sprang and Silman, 2013; APA, 2020; Esteves et al., 2020).

Furthermore, although there is evidence that spending confinement in a densely populated city is a risk factor, affecting people's stress (Özdin and Bayrak Özdin, 2020; Recchi et al., 2020; Tadesse et al., 2020), some authors have suggested that confinement in urban areas may even be a protective factor (Cao et al., 2020). It is possible that the population confined in urban areas would have less anxiety than those in rural areas as cities would tend to be more economically prosperous (Guessoum et al., 2020; Shigemura et al., 2020) and have better healthcare resources to cope with the disease (Cao et al., 2020).

No doubt one of the key conditions of confinement when it comes to explaining the stress response is the time that individuals have spent in confinement. We can expect that the longer the confinement, the greater the stress, and the worse the mental health (Hawryluck et al., 2004; Marjanovic et al., 2007; Reynolds et al., 2008; Brooks et al., 2020).

\section{Stress and Working Conditions}

As we noted above, when lockdown was declared, many workers stopped going to work and had to adapt to a change in their working conditions. Remote working is a clear example, although many people had their work temporarily suspended, and in the worst cases, indefinitely suspended. Given that in the current situation, defined by severe uncertainty, working conditions during confinement may affect populations' well-being and psychological health; in this study, we explore the extent to 
which they contribute to the stress response (see for example, Artazcoz et al., 2004; Brand et al., 2008; Bakioğlu et al., 2020).

Compared to those with permanent, full-time work, those most vulnerable to stress will be the unemployed or those with temporary or occasional work (Khan et al., 2002; DiGiovanni et al., 2004; Song et al., 2009; Ma et al., 2020; Mimoun et al., 2020; Shanahan et al., 2020). As we suggested above, economic security may act as a protective factor against depression, anxiety, and post-traumatic stress in the present situation (González-Sanguino et al., 2020).

\section{MATERIALS AND METHODS}

\section{Participants}

During the period of confinement, 2008 people (19.9\% men) responded voluntarily and anonymously to an online questionnaire aimed at discovering their situational stress responses and the coping strategies they were using. The respondents' were aged between 18 and 75 years old $\left(\mathrm{M}_{\text {age }}=38.30 ; S D=11.92\right)$. A total of 1745 respondents completed a Spanish version of the questionnaire, and 263 completed an English version. Although $63.2 \%$ of respondents were resident in Spain, we also received responses from various Latin American countries - 6\% from Argentina, 7.5\% from Ecuador, 7.6\% from Mexico, among others - and from residents in the United States (11.6\%).

\section{Instruments}

We examined a series of sociodemographic factors (gender, age, civil status, educational level, and income) to determine their relationship to the stress response to confinement. In addition to recording the amount of time (in weeks) that participants had been confined, we asked about their confinement situation (with parents, parents and children, single parent and children, with a partner, or alone) and the type of residence, where they were confined (urban, rural, or suburban/residential). We also asked participants about their working conditions prior to confinement (full-time, part-time, occasional or self-employed, homemaker, pensioner, or not working/studying), the conditions of work during confinement (remote working, attending work, mixed remote and in situ work, temporary suspension of work, or loss of employment) and their work-related expectations for after the confinement.

To evaluate people's levels of stress we used the 14-item Perceived Stress Scale (PSS-14) created by Cohen et al. (1983). This is a scale that has traditionally been reported to exhibit good internal and structural consistency (Cohen and Williamson, 1988; Remor, 2006; González and Landero, 2007; Campo et al., 2009; Cohen and Janicki-Deverts, 2012; Lee, 2012).

In line with theory and psychometric studies with PSS (both PSS-14 and PSS-10), in our study, it demonstrated a two-factor structure made up of elements worded positively and negatively (Taylor, 2015) which, with eigenvalues over 1, explain 52.54\% of the variance. The factorial analysis we carried out for the whole sample allowed us to differentiate between control of stress $(\alpha=0.83)$ and perceived stress $(\alpha=0.85)$. Both chi-square from the transformation of the determinant of the correlation matrix (Bartlett's sphericity of 0.000 ) and the size of the correlation coefficients $(\mathrm{KMO}=918)$ indicated the suitability of the factorial structure.

\section{Procedure}

Using non-probabilistic exponential snowball sampling, we constructed a single survey in both Spanish and English on the Microsoft Forms platform. On April 18, 2020, we published a direct link to the survey on various social networks and various other media both print and digital to publicize the request for participants in the study. The mean response time for the survey ranged between 15 and $20 \mathrm{~min}$, without a time limit.

To comply with the recommendations of the Ethics Committee for Research and Teaching at the University of A Coruña and the Declaration of Helsinki (AMM, 2017), we asked participants to confirm that they were over 18. They were informed of the voluntary, anonymous, confidential nature of their participation, and they were asked to give their informed consent to participate.

Once we had achieved a sufficiently large sample, and given the beginning of loosening lockdown measures in some countries, we closed access to the survey on May 19, 2020 and began data analysis using the SPSS statistical package.

\section{Data Analysis}

Predictor equations for stress during COVID-19 confinement were produced using logistical regression, following the forward stepwise regression procedure based on the Wald statistic. Three logistical regressions were performed using sociodemographic variables, confinement conditions, and work-related variables as predictors. The three cases included perceived stress (No $=0$ or Yes $=1$ ) as the criterion variable, referring to the mean in the Perceived Stress factor of the PSS-14 in the sample. The fit of the models was assessed using Nagelkerke's $R^{2}$ (Nagelkerke, 1991) and the percentage of correctly classified cases.

\section{RESULTS}

\section{Sociodemographic Variables and Perceived Stress During Confinement}

Considering gender, civil status, the level of education, and income levels, we produced a sociodemographic model in order to make estimations about the mean level of perceived stress during confinement (no stress $=0 /$ stress $=1$ ). The categorical variables in the regression equation were coded as described in Table $\mathbf{1 .}$

TABLE 1 | Frequencies and parameter coding (1) for the sociodemographic variables included in the regression equation.

\begin{tabular}{llccccc}
\hline & Frequency & \multicolumn{3}{c}{$\begin{array}{c}\text { Parameter } \\
\text { coding* }\end{array}$} \\
\cline { 4 - 6 } & & & & (1) & (2) & (3) \\
\hline \multirow{3}{*}{ Gender } & Male & 400 & 1 & & \\
& Female & 1,607 & 0 & & \\
& Married or stable partnership & 1,225 & 1 & 0 & 0 \\
& Separated or divorced & 134 & 0 & 1 & 0 \\
& Single & 619 & 0 & 0 & 1 \\
& Widowed & 29 & 0 & 0 & 0 \\
\hline
\end{tabular}

*Presence/absence of category. 
The final explanatory model of stress would allow the correct classification of $60.3 \%$ of the sample $\left(\chi^{2}=128.964 ; p=0.000\right)$, with better sensitivity in estimating above-average stress $(63.3 \%)$ than below-average stress (57.1\%; see Table 2 ).

The analysis of the final step suggested the inclusion of three sociodemographic models: gender, age, and income, with the remaining sociodemographic variables included initially - educational level and civil status - not providing

TABLE 2 | Omnibus tests on the sociodemographic model coefficients.

\begin{tabular}{rlrll}
\hline & & \multicolumn{1}{c}{$\chi^{2}$} & df & Sig. \\
\hline \multirow{3}{*}{ Step 1 } & Step & 83.305 & 1 & 0.000 \\
& Block & 83.305 & 1 & 0.000 \\
& Model & 83.305 & 1 & 0.000 \\
\multirow{3}{*}{ Step 2 } & Step & 38.189 & 1 & 0.000 \\
& Block & 121.493 & 2 & 0.000 \\
& Model & 121.493 & 2 & 0.000 \\
Step 3 & Step & 7.470 & 1 & 0.006 \\
& Block & 128.964 & 3 & 0.000 \\
& Model & 128.964 & 3 & 0.000 \\
\hline
\end{tabular}

TABLE 3 | Variables in the equation.

\begin{tabular}{lrrrrrr}
\hline & B & SE & Wald & df & $\boldsymbol{p}$ & $\operatorname{Exp(B)}$ \\
\hline Step 1 & & & & & & \\
Age & -0.200 & 0.022 & 80.362 & 1 & 0.000 & 0.818 \\
Constant & 0.784 & 0.099 & 63.250 & 1 & 0.000 & 2.190 \\
Step 2 $^{\text {b }}$ & & & & & & \\
Gender (1) & -0.721 & 0.119 & 36.967 & 1 & 0.000 & 0.486 \\
Age & -0.201 & 0.023 & 79.120 & 1 & 0.000 & 0.818 \\
Constant & 0.926 & 0.103 & 81.551 & 1 & 0.000 & 2.525 \\
Step 3 & & & & & & \\
Income level & -0.124 & 0.046 & 7.398 & 1 & 0.007 & 0.883 \\
Gender (1) & -0.717 & 0.119 & 36.494 & 1 & 0.000 & 0.488 \\
Age & -0.181 & 0.024 & 57.419 & 1 & 0.000 & 0.835 \\
Constant & 1.303 & 0.174 & 56.065 & 1 & 0.000 & 3.682 \\
\hline
\end{tabular}

avariable added in step 1: age.

${ }^{b}$ Variable added in step 2: gender.

'Variable added in step 3: income level. better information for the prediction of stress in confinement.

The stepwise regression process showed that age was the sociodemographic variable that most explained the perception of stress in confinement ( $W=57.419 ; p<0.001$ ), with gender making a reasonable contribution to this perception $(W=36.494$; $p<0.001)$. Income level would also explain perceived stress during confinement, with lower explanatory power $(\mathrm{W}=7.398$; $p<0.01$; see Table 3).

Although the percentage of variance explained was low (Nagelkerke's $\mathrm{R}^{2}=0.083$ ), looking at the parameter coding, we can interpret it as the perception of stress being higher in women than men, with the lowest stress in older people and those with higher reported incomes (see Table 3).

\section{Confinement Conditions and Perceived Stress}

In order to estimate the mean level of stress perceived by the population during confinement (no stress $=0 /$ stress $=1$ ), we included the length of time confined, the situation in the home, and the type of residence in the confinement conditions model. The categorical variables in this regression equation were coded as shown in Table 4.

The final explanatory model for the perceived level of stress allowed the correct classification of $55 \%$ of the sample $\left(\chi^{2}=30.662 ; p=0.000\right.$; see Table 5) with better sensibility when estimating above-average stress $(58.8 \%)$ than below-average stress $(51.3 \%)$.

TABLE 5 | Omnibus tests for the confinement conditions model coefficients.

\begin{tabular}{llrll}
\hline & & $\chi^{2}$ & $\boldsymbol{d f}$ & Sig. \\
\hline \multirow{3}{*}{ Step 1 } & Step & 8.290 & 1 & 0.004 \\
& Block & 8.290 & 1 & 0.004 \\
& Model & 8.290 & 1 & 0.004 \\
Step 2 & Step & 10.040 & 2 & 0.007 \\
& Block & 18.329 & 3 & 0.000 \\
\multirow{3}{*}{ Step 3 } & Model & 18.329 & 3 & 0.000 \\
& Step & 12.333 & 4 & 0.015 \\
& Block & 30.662 & 7 & 0.000 \\
& Model & 30.662 & 7 & 0.000
\end{tabular}

TABLE 4 | Frequencies and parameter coding (1) for the categorical variables related to the confinement conditions included in the regression equation.

\begin{tabular}{|c|c|c|c|c|c|c|}
\hline & & \multirow{2}{*}{ Frequency } & \multicolumn{4}{|c|}{ Parameter coding* } \\
\hline & & & (1) & (2) & (3) & (4) \\
\hline \multirow[t]{5}{*}{ Confined with... } & Alone/without children & 317 & 1 & 0 & 0 & 0 \\
\hline & With partner/without children & 354 & 0 & 1 & 0 & 0 \\
\hline & Single parent/with children & 244 & 0 & 0 & 1 & 0 \\
\hline & Two parents/with children & 854 & 0 & 0 & 0 & 1 \\
\hline & With parents & 117 & 0 & 0 & 0 & 0 \\
\hline \multirow[t]{3}{*}{ Type of residence } & Rural & 335 & 1 & 0 & & \\
\hline & Residential/Suburban & 366 & 0 & 1 & & \\
\hline & Urban & 1,185 & 0 & 0 & & \\
\hline
\end{tabular}

${ }^{*}$ Presence/absence of category. 
The stepwise regression procedure showed that the length of confinement $(W=8.815 ; p<0.01)$, the type of residence ( $W=10.017 ; p<0.01$ ), and the confinement situation (Confined with; $W=12,209 ; p<0.05)$ contributed to explaining the perception of stress in the population (see Table 6).

Although the variance explained was low (Nagelkerke's $R^{2}=0.022$ ), perceived stress would be lower in those confined with a partner, without children, and in residential or suburban areas (see Table 6). As expected, perceived stress would tend to be higher the longer the confinement (see Table 6).

\section{Work Situation and Stress of Confinement}

Considering people's work situation before confinement, during confinement, and their work-related expectations for after confinement, we produced a logistical regression model to assess the mean level of perceived stress (no stress $=0$ / stress $=1$ ). The categorical variables for this work situation model were coded as shown in Table 7.
The final explanatory model would allow the correct classification of $58.1 \%$ of the sample $\left(\chi^{2}=43.602 ; p=0.000\right)$ with better sensitivity when assessing below-average stress (66.1\%; see Table 8).

Analysis of the final step for the explanation of perceived stress suggests that the post-confinement work-related expectations $(W=24.6060 ; p<0.001)$ and people's normal pre-confinement work situations $(W=11.593$; $p<0.05)$ would contribute to their perceptions of stress. From these parameters, the work situation during confinement appears not to provide more information for the prediction of mean stress in the confined population.

Although the percentage of variance explained was low (Nagelkerke's $R^{2}=0.037$ ), looking at the parameter coding, we can interpret that perceived stress is higher the worse the post-confinement work-related expectations, and that the stress reported by those with full-time jobs is lower than the stress reported by those in other circumstances of work (see Table 9).

TABLE 6 | Variables in the equation.

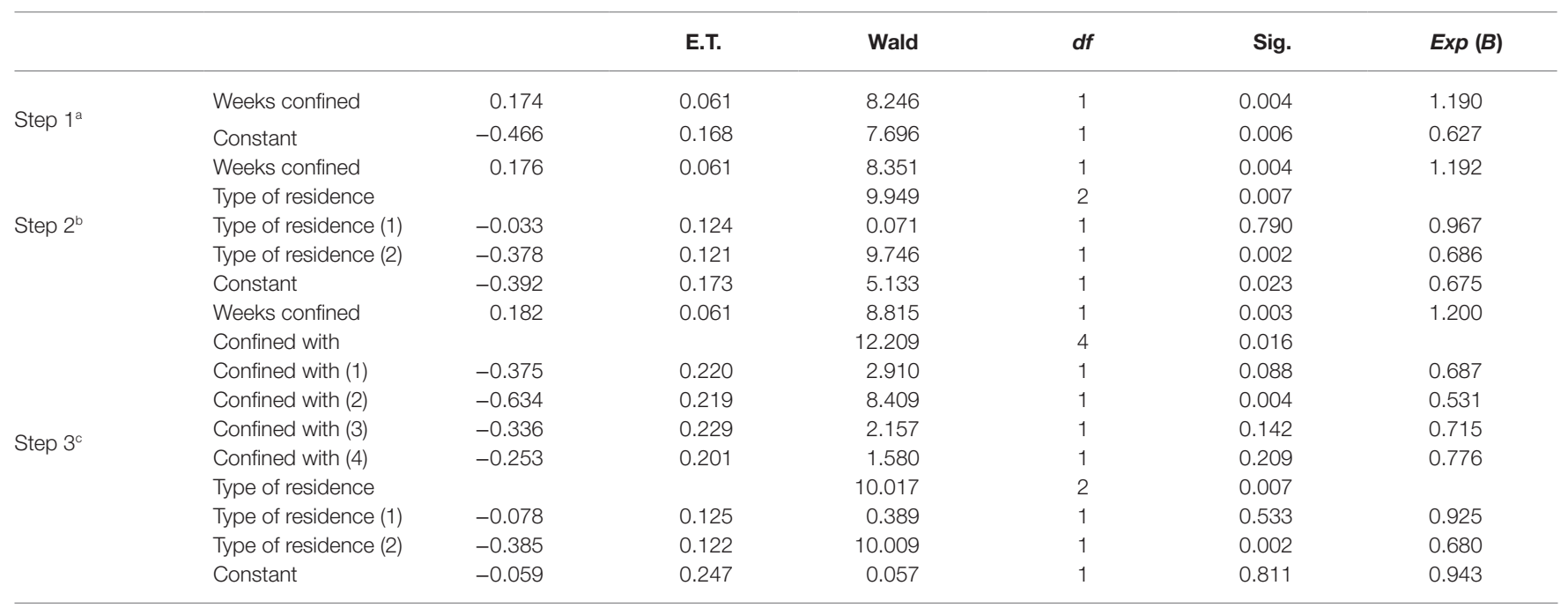

${ }^{a}$ Variables added in step 1: weeks confined.

${ }^{b}$ Variables added in step 2: type of residence.

'Variables added in step 3: confined with.

TABLE 7 | Frequencies and parameter (1) coding for the categorical variables related to the work situation included in the regression equation.

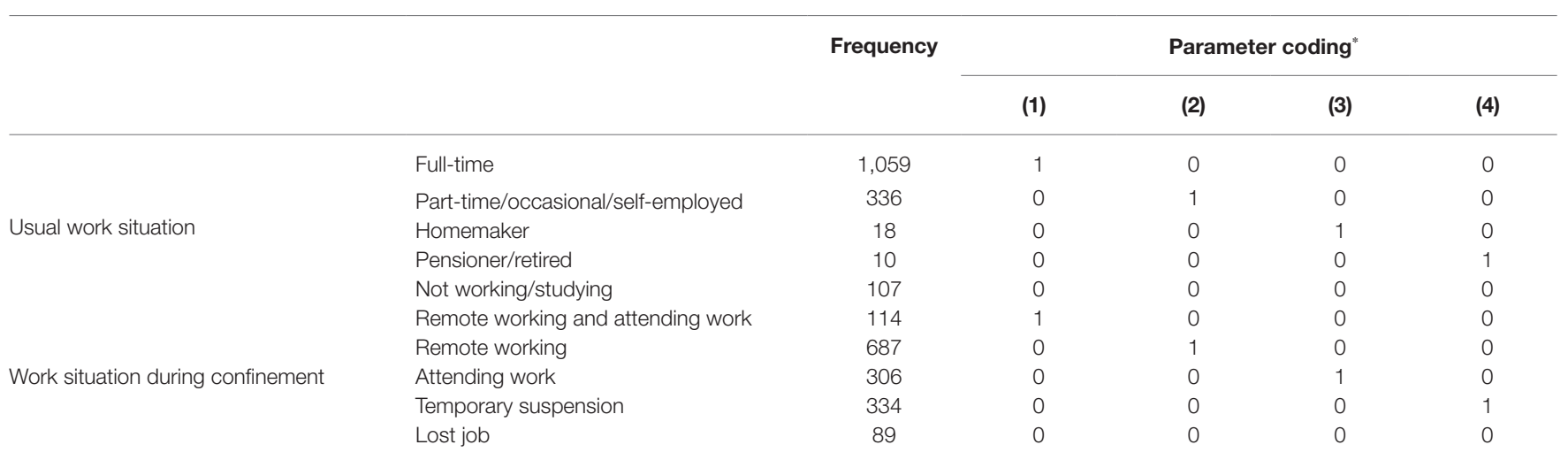

"Presence/absence of category. 


\section{DISCUSSION}

The results of this study may contribute to the recognition of factors underlying the stress of confined populations and may potentially inform possible future decisions in similar situations.

In line with the work by Brooks et al. (2020), the sociodemographic models demonstrate better explanatory power for stress in confinement than other models. Specifically, age (Taylor et al., 2008; Kang et al., 2020; Ozamiz-Etxebarria et al., 2020; Qiu et al., 2020; Shanahan et al., 2020; Wang et al., 2020b) and gender (Taylor et al., 2008; González-Sanguino et al., 2020; Kang et al., 2020; Pappa et al., 2020; Qiu et al., 2020; Wang et al., 2020a,b) seem to be the factors that best explain the perception of stress in confinement. The results also link low income and financial instability with the higher rates of stress and anxiety (Brooks et al., 2020; GonzálezSanguino et al., 2020; Lozano-Vargas, 2020; Shanahan et al., 2020; Wang et al., 2020a). The perception of confinement stress is higher among women than among men and decreases with age and with higher reported income.

Once age, gender, and income are considered, neither the level of education nor civil status provide better information in the explanation of stress in confinement (Hawryluck et al., 2004; Brooks et al., 2020; Lozano-Vargas, 2020; Wang et al., 2020a). Although one might expect that the level of education might make it easier for someone to properly interpret the information we are exposed to throughout confinement, the fact is that, in this study, we did not find differences in perceived stress according to this variable. It may be useful to explore potential differences in coping methods and in control of the stress response.

TABLE 8 | Omnibus tests for the workplace situation model coefficients.

\begin{tabular}{lllll}
\hline & & $\chi^{2}$ & $\boldsymbol{d f}$ & Sig. \\
\hline Step 1 & Step & 31.820 & 1 & 0.000 \\
& Block & 31.820 & 1 & 0.000 \\
\multirow{3}{*}{ Step 2 } & Model & 31.820 & 1 & 0.000 \\
& Step & 11.782 & 4 & 0.019 \\
& Block & 43.602 & 5 & 0.000 \\
& Model & 43.602 & 5 & 0.000
\end{tabular}

Although with more variance to explain than in the sociodemographic model, people's expectations about postconfinement work together with their pre-confinement work situation may to a large extent be estimators of emotional well-being - low perceived stress - in confined populations. In this regard, and as we hypothesized, perceived stress seems to be higher as people believe that their work situations will worsen post-confinement. Positive expectations were a protective factor against stress in confinement, enhancing the well-being of confined populations by strengthening self-efficacy and reducing behaviors associated with frustration and pessimism (Dubow et al., 2001; Besser and Shackelford, 2007; Bakioğlu et al., 2020; Molero et al., 2020; Salas-Nicás et al., 2020).

In line with results from previous studies, which reported part-time workers reporting more stress than full-time workers (DiGiovanni et al., 2004; Mimoun et al., 2020), those with full-time jobs may demonstrate less perceive stress during the periods of confinement. Those who work part-time, occasionally, or are self-employed would tend to have greater difficulties dealing with confinement because of the instability of the job market and/or lower incomes. Once the less negative workrelated expectations associated with more stable pre-confinement work situations are considered, the work situation during confinement does not provide more information to the prediction of people's stress (Ma et al., 2020; Mimoun et al., 2020; Shanahan et al., 2020).

Although the variance explained by the model using confinement conditions in the home is low, our results suggest an increase in the rates of stress according to the length of confinement (Hawryluck et al., 2004; Marjanovic et al., 2007; Reynolds et al., 2008; Brooks et al., 2020; Taylor et al., 2020) and indicate a profile of reduced stress in stable couples without children (Sprang and Silman, 2013; APA, 2020; Esteves et al., 2020; Ma et al., 2020) confined in residential or suburban areas (Özdin and Bayrak Özdin, 2020; Recchi et al., 2020; Tadesse et al., 2020).

The difficulty of couples with children in accessing their support networks during the current confinement due to COVID-19 (Ma et al., 2020) may contribute to the levels of reported stress, and suburban or residential areas may combine the best qualities of urban and rural areas, contributing to a

TABLE 9 | Variables in the equation.

\begin{tabular}{|c|c|c|c|c|c|c|c|}
\hline & & B & E.T. & Wald & $d f$ & Sig. & $\operatorname{Exp}(B)$ \\
\hline \multirow[t]{2}{*}{ Step $1^{a}$} & Work expectations & -0.533 & 0.095 & 31.130 & 1 & 0.000 & 0.587 \\
\hline & Constant & 0.838 & 0.164 & 25.960 & 1 & 0.000 & 2.311 \\
\hline \multirow[t]{7}{*}{ Step $2^{\mathrm{b}}$} & Work expectations & -0.480 & 0.097 & 24.660 & 1 & 0.000 & 0.619 \\
\hline & Usual work & & & 11.593 & 4 & 0.021 & \\
\hline & Usual work (1) & -0.612 & 0.214 & 8.207 & 1 & 0.004 & 0.542 \\
\hline & Usual work (2) & -0.347 & 0.231 & 2.251 & 1 & 0.134 & 0.707 \\
\hline & Usual work (3) & -0.103 & 0.531 & 0.038 & 1 & 0.846 & 0.902 \\
\hline & Usual work (4) & -0.489 & 0.669 & 0.535 & 1 & 0.465 & 0.613 \\
\hline & Constant & 1.257 & 0.248 & 25.616 & 1 & 0.000 & 3.515 \\
\hline
\end{tabular}

avariables added in step 1: work expectations.

${ }^{b}$ Variables added in step 2: usual work. 
smaller stress response to confinement (Özdin and Bayrak Özdin, 2020; Recchi et al., 2020; Tadesse et al., 2020). associated with confinement in residential areas would not have the negative characteristics associated with confinement in rural areas, as residential areas are relatively closer to more urban areas, they are associated with greater economic prosperity, with better connections to public services, and better healthcare conditions in the fight against the pandemic (Cao et al., 2020; Guessoum et al., 2020; Shigemura et al., 2020).

\section{DATA AVAILABILITY STATEMENT}

The datasets presented in this study can be found in online repositories. The names of the repository/repositories and accession number(s) can be found at doi: 10.5281/zenodo.4020364.

\section{ETHICS STATEMENT}

The studies involving human participants were reviewed and approved by the Ethics Committee of University of A Coruña. The patients/participants provided their written informed consent to participate in this study.

\section{REFERENCES}

Abidin, R. R. (1997). "Parenting stress index: A measure of the parent child system," in Evaluating stress: A book of resources. eds. C. Zalaquett and R. Woods (Lanham: Scarecrow Press, Inc.), 277-291.

AMM (2017). Declaración de Helsinki sobre principios éticos para las investigaciones médicas en seres humanos. Available at: https://www.wma. net/es/policies-post/declaracion-de-helsinki-de-la-amm-principios-eticos-paralas-investigaciones-medicas-en-seres-humanos/ (Accessed June 22, 2020).

APA (2020). Stress in the Time of COVID-19. American Psychological Association. Available at: https://www.apa.org/news/press/releases/stress/2020/stress-inamerica-covid.pdf (Accessed June 22, 2020).

Artazcoz, L., Benach, J., Borrell, C., and Cortès, I. (2004). Unemployment and mental health: understanding the interactions among gender, family roles, and social class. Am. J. Public Health 94, 82-88. doi: 10.2105/ ajph.94.1.82

Bakioğlu, F., Korkmaz, O., and Ercan, H. (2020). Fear of COVID-19 and positivity: mediating role of intolerance of uncertainty, depression, anxiety, and stress. Int. J. Ment. Health Addict. 1-14. doi: 10.1007/s11469-020-00331-y [Epub ahead of print].

Besser, A., and Shackelford, T. K. (2007). Mediation of the effects of the big five personality dimensions on negative mood and confirmed affective expectations by perceived situational stress: A quasi-field study of vacationers. Personal. Individ. Differ. 42, 1333-1346. doi: 10.1016/j.paid.2006.10.011

Brand, J. E., Levy, B. R., and Gallo, W. T. (2008). Effects of layoffs and plant closings on subsequent depression among older workers. Res. Aging 30, 701-721. doi: 10.1177/0164027508322574

Brooks, S. K., Webster, R. K., Smith, L. E., Woodland, L., Wessely, S., Greenberg, N., et al. (2020). The psychological impact of quarantine and how to reduce it: rapid review of the evidence. Lancet 395, 912-920. doi: 10.1016/ s0140-6736(20)30460-8

Campo, A., Bustos, G., and Romero, A. (2009). Consistencia interna y dimensionalidad de la Escala de Estrés Percibido (EEP-10 y EEP-14) en una muestra de universitarias de Bogotá, Colombia. Aquichan 9, 271-280.

Cao, W., Fang, Z., Hou, G., Han, M., Xu, X., Dong, J., et al. (2020). The psychological impact of the COVID-19 epidemic on college students in China. Psychiatry Res. 287:112934. doi: 10.1016/j.psychres.2020.112934

\section{AUTHOR CONTRIBUTIONS}

AV and IP conceived the presented idea. SR developed the theory and performed the computations. AV verified the analytical methods and supervised the project. IP encouraged TV and RG-S to investigate stress in COVID-19 and supervised the findings of this work. TV wrote the manuscript with support from RG-S, FD, and IP who fabricated the first sample. SR and $\mathrm{AV}$ helped to supervise the project and conceived the original idea. VT, RG-S, and FD developed the theoretical formalism. SR and IP performed the analytic calculations and the numerical simulations. All authors provided critical feedback, discussed the result, and also carried out the experiment. All authors contributed to the article and approved the submitted version.

\section{FUNDING}

This study was funded by the research project EDU2013-44062-P (MINECO) and EDU2017-82984-P (MEIC) and the FPU program (FPU18/02191) and the FPI program (PRE2018-084938) from the Ministry of Science, Innovation, and Universities to two of the authors.

Cohen, S., and Herbert, T. B. (1996). Health psychology: psychological factors and physical disease from the perspective of human psychoneuroimmunology. Annu. Rev. Psychol. 47, 113-142. doi: 10.1146/annurev.psych.47.1.113

Cohen, S., and Janicki-Deverts, D. (2012). Who's stressed? Distributions of psychological stress in the United States in probability samples from 1983, 2006, and 2009. J. Appl. Soc. Psychol. 42, 1320-1334. doi: 10.1111/j.1559-1816.2012.00900.x

Cohen, S., Kamarck, T., and Mermelstein, R. (1983). A global measure of perceived stress. J. Health Soc. Behav. 24, 385-396. doi: 10.2307/2136404

Cohen, S., and Williamson, G. (1988). "Perceived stress in a probability sample of the United States," in The Claremont symposium on applied social psychology. The social psychology of health. eds. S. Spacapan and S. Oskamp (Sage Publications), 31-67.

Cohen, S., and Williamson, G. M. (1991). Stress and infectious disease in humans. Psychol. Bull. 109, 5-24. doi: 10.1037/0033-2909.109.1.5

Cohen, S., and Wills, T. A. (1985). Stress, social support, and the buffering hypothesis. Psychol. Bull. 98, 310-357. doi: 10.1037/0033-2909.98.2.310

DiGiovanni, C., Conley, J., Chiu, D., and Zaborski, J. (2004). Factors influencing compliance with quarantine in Toronto during the 2003 SARS outbreak. Biosecur. Bioterror. 2, 265-272. doi: 10.1089/bsp.2004.2.265

Dubow, E. F., Arnett, M., Smith, K., and Ippolito, M. F. (2001). Predictors of future expectations of inner-city children: a 9-month prospective study. J. Early Adolesc. 21, 5-28. doi: 10.1177/0272431601021001001

Durán, M. M. (2010). Bienestar psicológico: el estrés y la calidad de Vida en el contexto laboral. RNA 1, 71-84. doi: 10.22458/rna.vli1.285

Esteves, L., Ashencaen Crabtree, S., and Hemingway, A. (2020). Impacts of C-19 lockdown on the work-life balance of BU academics-preliminary results. Poole, England: Bournemouth University. Available at: http://eprints. bournemouth.ac.uk/34070/ (Accessed June 21, 2020).

González, M. T., and Landero, R. (2007). Factor structure of the perceived stress scale (PSS) in a sample from Mexico. Span. J. Psychol. 10, 199-206. doi: $10.1017 / S 1138741600006466$

González-Sanguino, C., Ausín, B., Castellanos, M. A., Saiz, J., López-Gómez, A., Ugidos, C., et al. (2020). Mental health consequences during the initial stage of the 2020 coronavirus pandemic (COVID-19) in Spain. Brain Behav. Immun. 87, 172-176. doi: 10.1016/j.bbi.2020.05.040

Greenberg, N., Carr, J. A., and Summers, C. H. (2002). Causes and consequences of stress. Integr. Comp. Biol. 42, 508-516. doi: 10.1093/icb/42.3.508 
Guessoum, S. B., Lachal, J., Radjack, R., Carretier, E., Minassian, S., Benoit, L., et al. (2020). Adolescent psychiatric disorders during the COVID-19 pandemic and lockdown. Psychiatry Res. 291:113264. doi: 10.1016/j.psychres.2020.113264

Hawryluck, L., Gold, W. L., Robinson, S., Pogorski, S., Gale, S., and Styra, R. (2004). SARS control and psychological effects of quarantine, Toronto, Canada. Emerg. Infect. Dis. 10, 1206-1212. doi: 10.3201/eid1007.030703

Jalloh, M. F., Li, W., Bunnell, R. E., Ethier, K. A., O'Leary, A., Hageman, K. M., et al. (2018). Impact of Ebola experiences and risk perceptions on mental health in Sierra Leone, July 2015. BMJ Glob. Health 3:e000471. doi: 10.1136/ bmigh-2017-000471

Kang, L., Ma, S., Chen, M., Yang, J., Wang, Y., Li, R., et al. (2020). Impact on mental health and perceptions of psychological care among medical and nursing staff in Wuhan during the 2019 novel coronavirus disease outbreak: a cross-sectional study. Brain Behav. Immun. 87, 11-17. doi: 10.1016/j. bbi.2020.03.028

Khan, S., Murray, R. P., and Barnes, G. E. (2002). A structural equation model of the effect of poverty and unemployment on alcohol abuse. Addict. Behav. 27, 405-423. doi: 10.1016/S0306-4603(01)00181-2

Lee, E. H. (2012). Review of the psychometric evidence of the perceived stress scale. Asian Nurs. Res. 6, 121-127. doi: 10.1016/j.anr.2012.08.004

Lozano-Vargas, A. (2020). Impacto de la epidemia del coronavirus (COVID-19) en la salud mental del personal de salud y en la población general de China. Rev. Neuropsiquiatr. 83, 51-56. doi: 10.20453/rnp.v83i1.3687

Ma, Z. F., Zhang, Y., Luo, X., Li, X., Li, Y., Liu, S., et al. (2020). Increased stressful impact among general population in mainland China amid the COVID-19 pandemic: a nationwide cross-sectional study conducted after Wuhan city's travel ban was lifted. Int. J. Soc. Psychiatry 66, 770-779. doi: 10.1177/0020764020935489

Marjanovic, Z., Greenglass, E. R., and Coffey, S. (2007). The relevance of psychosocial variables and working conditions in predicting nurses' coping strategies during the SARS crisis: an online questionnaire survey. Int. J. Nurs. Stud. 44, 991-998. doi: 10.1016/j.ijnurstu.2006.02.012

McEwen, B. S. (1998). Protective and damaging effects of stress mediators. $N$. Engl. J. Med. 338, 171-179. doi: 10.1056/NEJM199801153380307

Meléndez, J. C., Agustí, A. I., Delhom, I., Rodríguez, M. F. R., and Satorres, E. (2018). Bienestar subjetivo y psicológico: comparación de jóvenes y adultos mayores subjective and psychological well-being: young and older adults' comparison. Summa psicol. UST 15, 18-24. doi: 10.18774/0719-448x.2018.15.335

Mimoun, E., Ben Ari, A., and Margalit, D. (2020). Psychological aspects of employment instability during the COVID-19 pandemic. Psychol. Trauma Theory Res. Pract. Policy 12(S1), S183-S185. doi: 10.1037/tra0000769

Min, S., Sub, W., Cho, A. R., Kim, T., and Kyung, J. (2018). Psychological impact of the 2015MERS outbreak on hospital workers and quarantined hemodialysis patients. Compr. Psychiatry 87, 123-127. doi: 10.1016/j. comppsych.2018.10.003

Mohammed, A., Sheikh, T. L., Gidado, S., Poggensee, G., Nguku, P., Olayinka, A., et al. (2015). An evaluation of psychological distress and social support of survivors and contacts of Ebola virus disease infection and their relatives in Lagos, Nigeria: a cross sectional study-2014. BMC Public Health 15:824. doi: 10.1186/s12889-015-2167-6

Molero, M., Pérez-Fuentes, M., Soriano, J. G., Oropesa, N. F., Simón, M., Sisto, M., et al. (2020). Factores psicológicos en situaciones de cuarentena: una revisión sistemática. Eur. J. Med. Res. 6, 109-120. doi: 10.30552/ejhr.v6i1.206

Nagelkerke, N. J. (1991). A note on a general definition of the coefficient of determination. Biometrika 78, 691-692. doi: 10.1093/biomet/78.3.691

Ozamiz-Etxebarria, N., Dosil-Santamaria, M., Picaza-Gorrochategui, M., and Idoiaga-Mondragon, N. (2020). Niveles de estrés, ansiedad y depresión en la primera fase del brote del COVID-19 en una muestra recogida en el norte de España. Cad. Saude Publica 36, e00054020-e00054029. doi: 10.1590/0102-311x00054020

Özdin, S., and Bayrak Özdin, Ş. (2020). Levels and predictors of anxiety, depression and health anxiety during COVID-19 pandemic in Turkish society: The importance of gender. Int. J. Soc. Psychiatry 66, 504-511. doi: 10.1177/0020764020927051

Pappa, S., Ntella, V., Giannakas, T., Giannakoulis, V. G., Papoutsi, E., and Katsaounou, P. (2020). Prevalence of depression, anxiety, and insomnia among healthcare workers during the COVID-19 pandemic: a systematic review and meta-analysis. Brain Behav. Immun. 88, 901-907. doi: 10.1016/j. bbi.2020.05.026
Qiu, J., Shen, B., Zhao, M., Wang, Z., Xie, B., and Xu, Y. (2020). A nationwide survey of psychological distress among Chinese people in the COVID-19 epidemic: implications and policy recommendations. Gen Psychiatr. 33:e100213. doi: 10.1136/gpsych-2020-100213

Quick, J. D., Horn, R. S., and Quick, J. C. (1987). Health consequences of stress. J. Organ. Behav. Manage. 8, 19-36. doi: 10.1300/J075v08n02_03

Raphael, J. L., Zhang, Y., Liu, H., and Giardino, A. P. (2010). Parenting stress in US families: implications for pediatric healthcare utilization. Child Care Health Dev. 36, 216-224. doi: 10.1111/j.1365-2214.2009.01052.x

Recchi, E., Ferragina, E., Helmeid, E., Pauly, S., Safi, M., Sauger, N., et al. (2020). The "eye of the hurricane" paradox: an unexpected and unequal rise of well-being during the Covid-19 lockdown in France. Res. Soc. Stratif 68:100508. doi: 10.1016/j.rssm.2020.100508

Remor, E. (2006). Psychometric properties of a European Spanish version of the perceived stress scale (PSS). Span. J. Psychol. 9, 86-93. doi: 10.1017/ S1138741600006004

Reynolds, D. L., Garay, J. R., Deamond, S. L., Moran, M. K., Gold, W., and Styra, R. (2008). Understanding, compliance and psychological impact of the SARS quarantine experience. Epidemiol. Infect. 136, 997-1007. doi: $10.1017 /$ S0950268807009156

Salas-Nicás, S., Llorens-Serrano, C., Navarro, A., and Moncada, S. (2020). Condiciones de trabajo, inseguridad y salud en el contexto del COVID-19: estudio de la población asalariada de la encuesta COTS. Barcelona: UAB, ISTAS-CCOO.

Sánchez, G. J. (2013). El efecto del estrés en la salud y el bienestar de los estudiantes universitarios. doctoral thesis. Las Palmas de Gran Canaria, España: Universidad de las palmas de gran canaria.

Shanahan, L., Steinhoff, A., Bechtiger, L., Murray, A. L., Nivette, A., Hepp, U., et al. (2020). Emotional distress in young adults during the COVID-19 pandemic: evidence of risk and resilience from a longitudinal cohort study. Psychol. Med. 1-10. doi: 10.1017/s003329172000241x [Epub ahead of print].

Shigemura, J., Ursano, R. J., Morganstein, J. C., Kurosawa, M., and Benedek, D. M. (2020). Public responses to the novel 2019 coronavirus $(2019-\mathrm{nCoV})$ in Japan: mental health consequences and target populations. Psychiatry Clin. Neurosci. 74:281. doi: 10.1111/pcn.12988

Song, Z., Uy, M. A., Zhang, S., and Shi, K. (2009). Daily job search and psychological distress: evidence from China. Hum. Relat. 62, 1171-1197. doi: $10.1177 / 0018726709334883$

Sprang, G., and Silman, M. (2013). Posttraumatic stress disorder in parents and youth after health-related disasters. Disaster Med. Public Health Prep. 7, 105-110. doi: 10.1017/dmp.2013.22

Tadesse, A. W., Mihret, S., Biset, G., and Muluneh, A. (2020). Psychological impacts of COVID-19 among college students in Dessie town, Amhara region, Ethiopia; cross-sectional study. Research Square [Preprint]. doi: 10.21203/rs.3.rs-38100/v1

Taylor, J. M. (2015). Psychometric analysis of the ten-item perceived stress scale. Psychol. Assess. 27, 90-101. doi: 10.1037/a0038100

Taylor, M. R., Agho, K. E., Stevens, G. J., and Raphael, B. (2008). Factors influencing psychological distress during a disease epidemic: data from Australia's first outbreak of equine influenza. BMC Public Health 8:347. doi: 10.1186/1471-2458-8-347

Taylor, S., Landry, C. A., Paluszek, M. M., Fergus, T. A., McKay, D., and Asmundson, G. J. (2020). COVID stress syndrome: concept, structure, and correlates. Depress. Anxiety 37, 706-714. doi: 10.1002/da.23071

Trujillo, H. M., and González-Cabrera, J. (2007). Propiedades psicométricas de la versión española de la "Escala de estrés percibido" (EEP). Psicol. Conductual. 15, 457-477.

Wang, C., Pan, R., Wan, X., Tan, Y., Xu, L., Ho, C. S., et al. (2020a). Immediate psychological responses and associated factors during the initial stage of the 2019 coronavirus disease (COVID-19) epidemic among the general population in China. Int. J. Environ. Res. Public Health 17:1729. doi: 10.3390/ ijerph17051729

Wang, C., Pan, R., Wan, X., Tan, Y., Xu, L., Mcintyre, R. S., et al. (2020b). A longitudinal study on the mental health of general population during the COVID-19 epidemic in China. Brain Behav. Immun. 87, 40-48. doi: 10.1016/j.bbi.2020.04.028

Conflict of Interest: The authors declare that the research was conducted in the absence of any commercial or financial relationships that could be construed as a potential conflict of interest. 
Copyright (C) 2021 Rodríguez, Valle, Piñeiro, González-Suárez, Díaz and Vieites. This is an open-access article distributed under the terms of the Creative Commons Attribution License (CC BY). The use, distribution or reproduction in other forums is permitted, provided the original author(s) and the copyright owner(s) are credited and that the original publication in this journal is cited, in accordance with accepted academic practice. No use, distribution or reproduction is permitted which does not comply with these terms. 